\title{
PREFABRICATION IN THE AUSTRALIAN CONTEXT
}

\author{
Hong Xian Li *, Mark Luther * and Anthony Mills * \\ * Deakin University, School of Architecture and Built Environment, Australia \\ e-mails: hong.li@deakin.edu.au, mark.luther@ deakin.edu.au, anthony.mills@deakin.edu.au
}

\begin{abstract}
Australia actually has a long history with prefabricated building since its early settlement days. However, methods of prefabrication have, until the past decade, been relatively few and almost nonexistent with the exception of relocatable school building or portables. The revival of interest in prefabricated building has been quite recent, involving a few selective construction companies, and the interpretation of prefabrication has mainly resulted in a 'volumetric' product as the solution. In response to this, first the paper describes the profile of prefabrication in Australia, and then addresses a pathway for the processes and methods to pre-fabrication based on the identified challenges in Australia. This paper presents these ideas and discusses the up and coming directions of prefabrication in Australia.
\end{abstract}

Keywords: prefabrication, Australia, volumetric, panelised, SIP panels.

\section{HISTORY OF PREFABRICATION IN AUSTRALIA}

Early in the 17th century, prefabrication was utilised to form the built environment in Australia, when Europeans discovered this glory country. Due to the shortage of skilled labour and manufactured building materials, building components were manufactured in UK, or a few other places in Asia, and delivered to Australia where they were then assembled. The manufactured buildings included settleres sottages, grand villas, churches and schools, and could be ordered referring to illustrated pattern books and catalogues. It was recorded that 15,960 wooden houses and 6,369 iron buildings were delivered to Melbourne in 1853, however, none of these buildings remain, probably because of the resale value of the metal [1].

An excellent remaining example of Australian prefabricated buildings in the ancient era is Corio Villa located in Geelong, as illustrated in Figure 1 and Figure 2. The main building components were manufactured in Edinburgh, Scotland around 1854 to 1855, and then erected in Geelong between 1855 and 1856. Corio Villa is prefabricated with cast iron, and the house was shipped to Geelong in boxes in 1855. Corio Villa is recognised as the first cast iron property and the only example of this prefab building model in the world, since the factory burnt down soon after Corio Villa was made [1].

In recent centuries, there was urgency of prefabricated buildings due to a period of major infrastructure projects together with the rapid population growth of the baby boomer era [2].

\section{CURRENT PROFILE OF PREFABRICATION IN AUSTRALIA}

Currently, modular construction and pre-fabrication represents 3\% of Australia"s $\$ 150$ billion construction industry, and it is predicted that nearly $10 \%$ or around $\$ 15$ billion of the total construction industry in Australia can be prefabricated within five years [3]. 


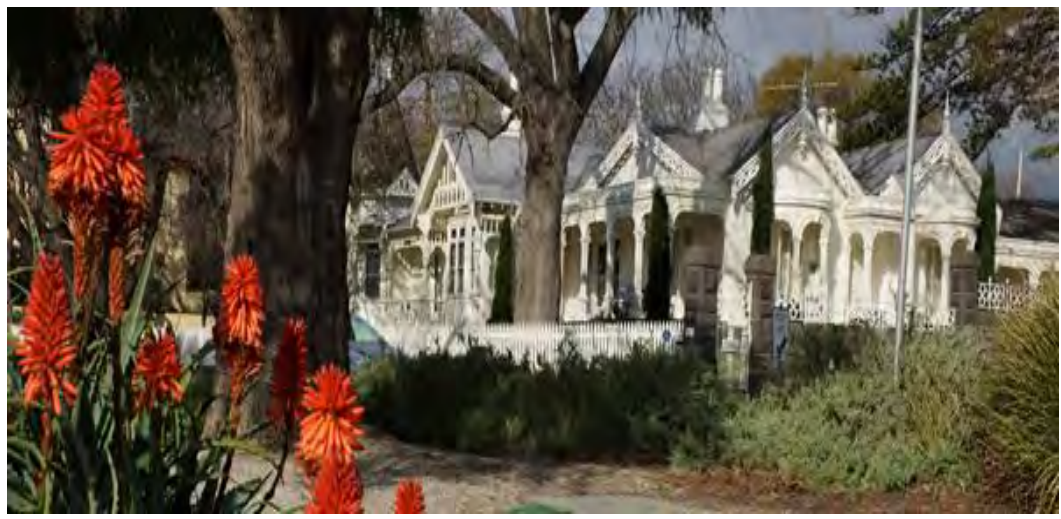

Figure 1. Corio Villa Building in Geelong.

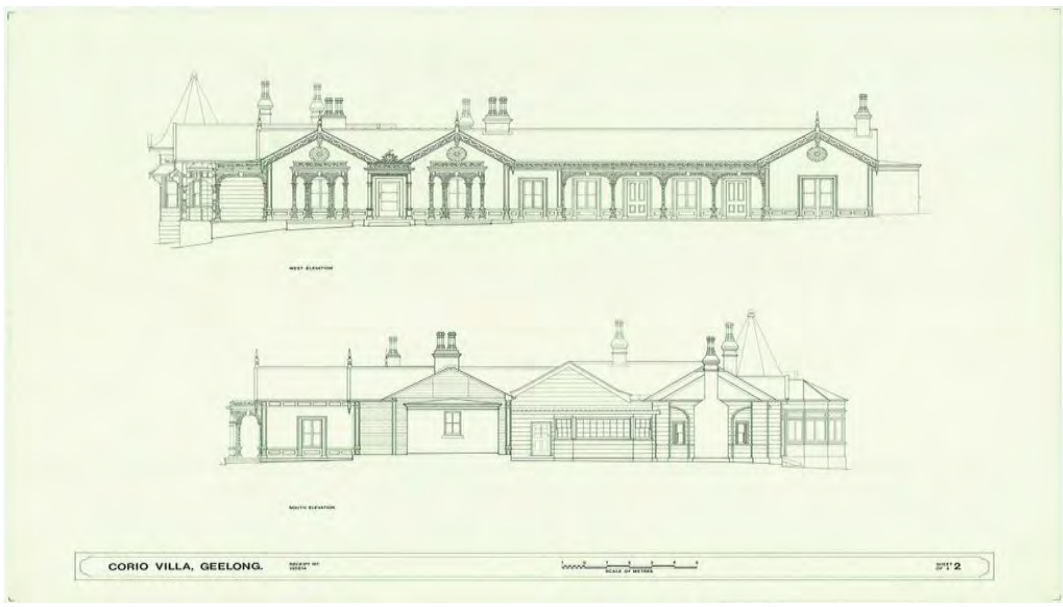

Figure 2. Corio Villa Drawing.

(Source: http://builtoffsite.com.au/issue-01/historic-perspective-everything-old-new/)

There are various types of prefabrication methods and prefabricated building components, corresponding to different levels of prefabrication, including: (1) modular: box-shaped volumetric (3D) building units, which can be assembled with other units or building components on-site; (2) panels: 2D prefabricated building components such as wall panels and floor panels, among which panels (typically wood panels) with insulation added are named as Structural Insulated Panels (SIP); (3) pods: volumetric pre-assembly building components, such as bathroom or kitchen units; and (4) building components: manufactured and preassembled building components, such as windows and doors.

Steinhardt et al (2013) identified the manufacturers and builders using prefabrication technology across Australia, and compared the prefabrication in Australia with that of representative countries worldwide. Based on the data identified by Steinhardt et al (2013), we display the prefabrication in Australia and the distribution in Figure 3 to Figure 5. 


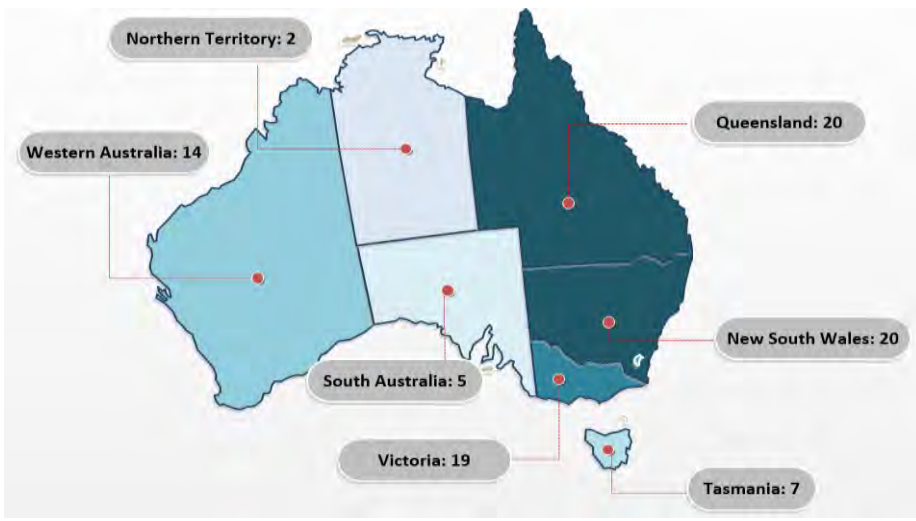

Figure 3: Modular Manufacturer/Builder Distribution.

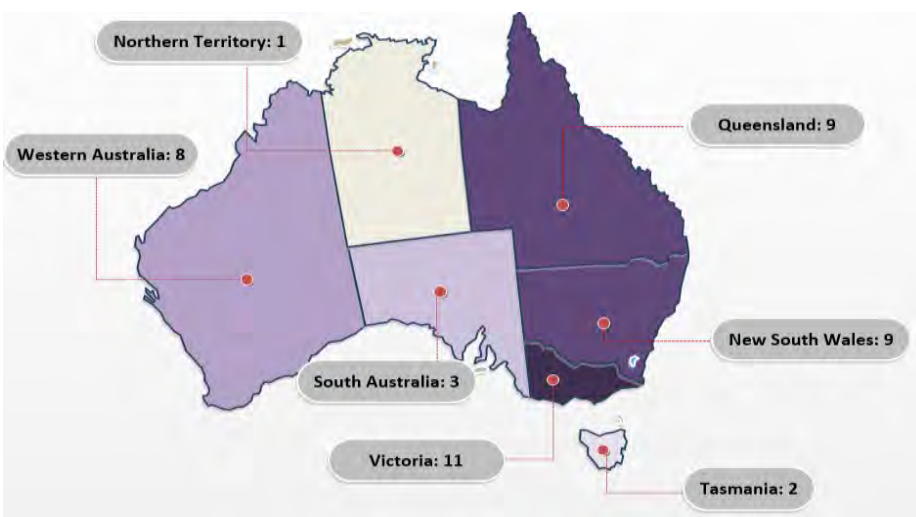

Figure 4: Precast Concrete Panel Manufacturer Distribution.

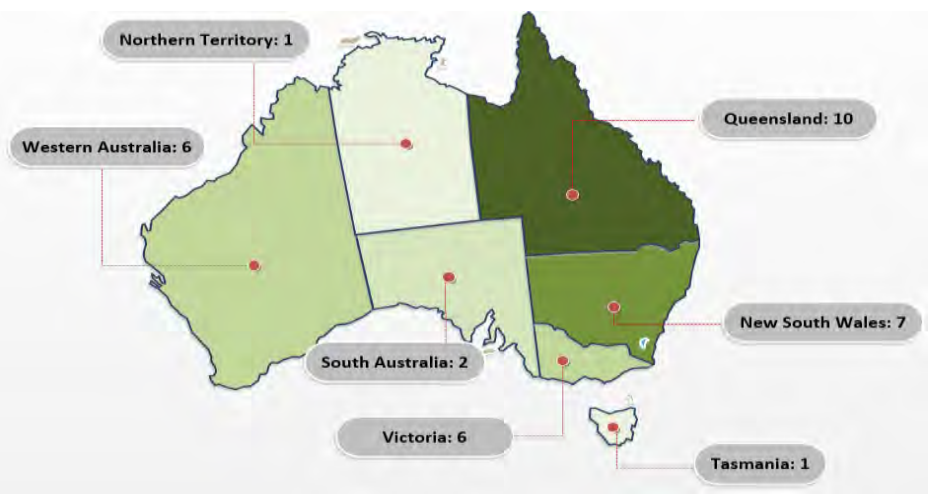

Figure 5: SIP Manufacturer Distribution. 
In terms of material types, steel, concrete, and wood are all used for prefabrication in Australia. The representative buildings with different material types include: (1) The Star Sydney with steel structure, as depicted in Figure 6, (2) Berry Sports and Recreation Centre NSW with precast concrete, as displayed in Figure 7, and (3) Library at The Dock with Cross Laminated Timber (CLT) wood structure in Melbourne, as shown in Figure 8. Recently, the application of CLT has gained attention in Australia. CLT has been applied in a 10-story apartment building (Forte) in Melbourne, and a CLT plant is being constructed in NSW by Lendlease Group.

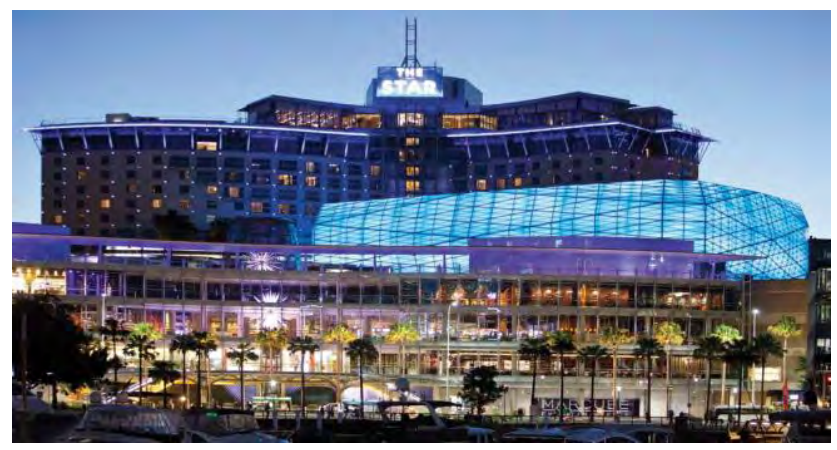

Figure 6: The Star Sydney.

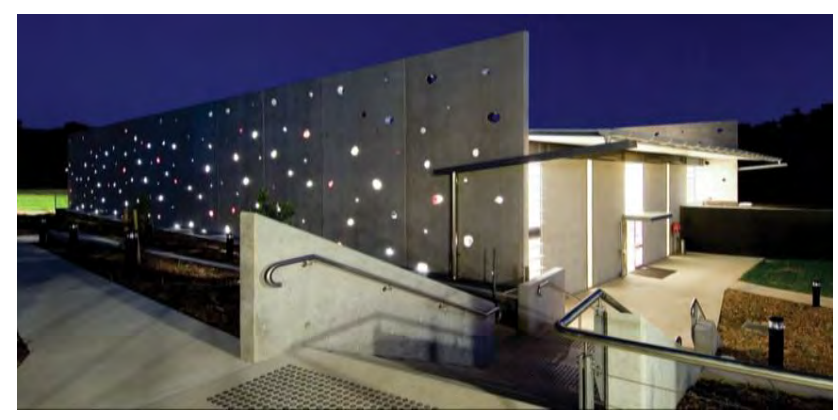

Figure 7: Berry Sports and Recreation Centre NSW.

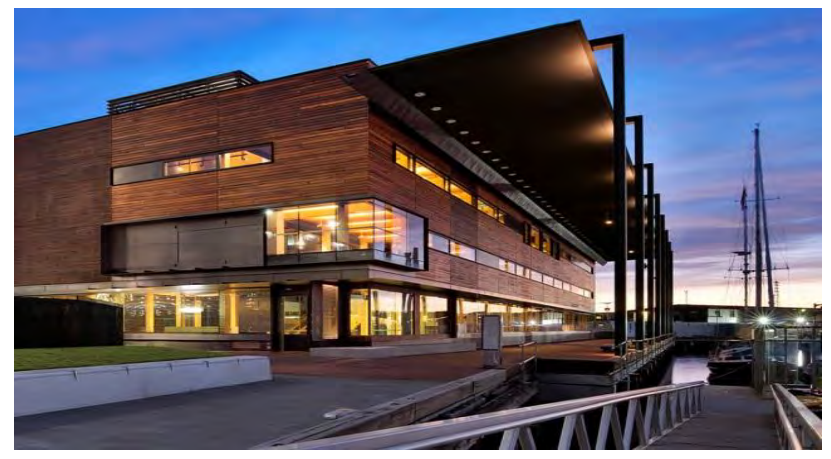

Figure 8: Library at The Dock, Melbourne. 
Luther (2009) evaluated several prefabricated building systems in terms of materials, flexibility, structural integrity, delivery and constructability, and confirmed the benefits of prefabrication, including design diversity, waste reduction, and integration of renewable systems and optimal performance. Furthermore, Steinhardt et al (2014) reported that the majority of builders were open to increasing their use of prefabrication in housing, and also found there was also a significantly higher reported use of prefabrication than previous studies had reported.

\section{A CASE STUDY OF PREFABRICATION IN AUSTRALIA}

Australiae"s tallest prefabricated tower is the La Trobe Tower apartment building, located in the Melbourne"s CBD. The La Trobe Tower is 133-metre high with 44 levels, including multiple functions and units: 206 units of one or two bedroom apartments, common area on level 15 featuring a lounge, outdoor terrace, kitchenette and gymnasium, and glass façade with design reflecting musical heritage of this area. The tallest prefabricated tower was built using an innovative new prefabricated construction method, Hickory Building System (HBS), developed by Hickory Group. The La Trobe Tower was initially planned to be built using conventional construction method, and was transferred to a prefabrication solution due to the constraints of site access in Melbourne"s CBD and delivery time. It was ultimately delivered around $30 \%$ faster than comparable projects.

HBS is a prefab system integrating the core, shear walls, bathrooms and façade of a building into the structure system, which is then in parallel with on-site works. The building process begins with an engineered concrete floor and load bearing columns, and then prefabricated integrated units of wet areas and building façades are installed on-site. The structural architecture has been designed to span across multiple modules to generate flexible floor spaces, and an interlocking and sealing system has also been designed to minimise onsite work.

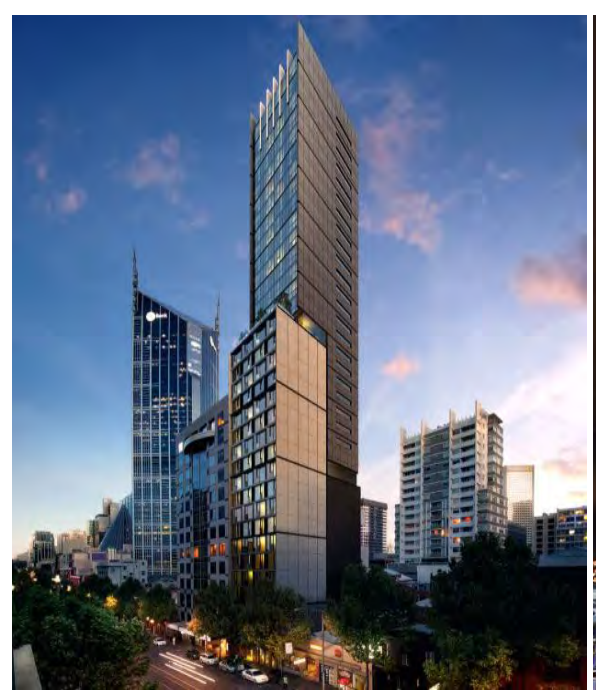

Figure 9: La Trobe Tower.

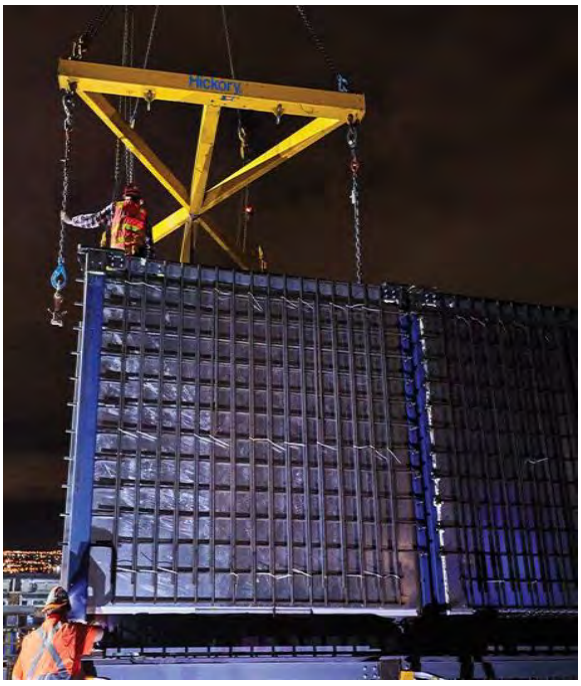

Figure 10: Hickory Building System I. 


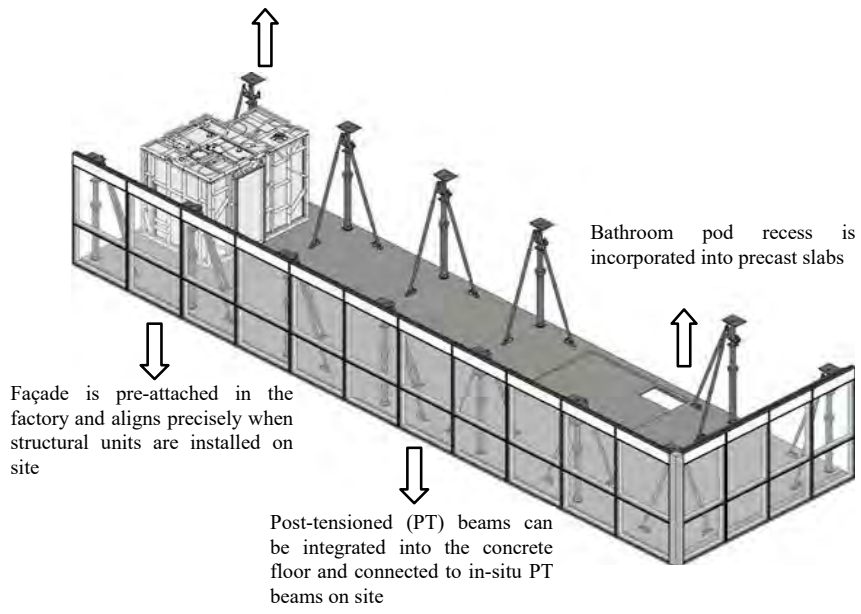

Figure 11: Hickory Building System II.

(Source: Hickory Building Innovation (2017)

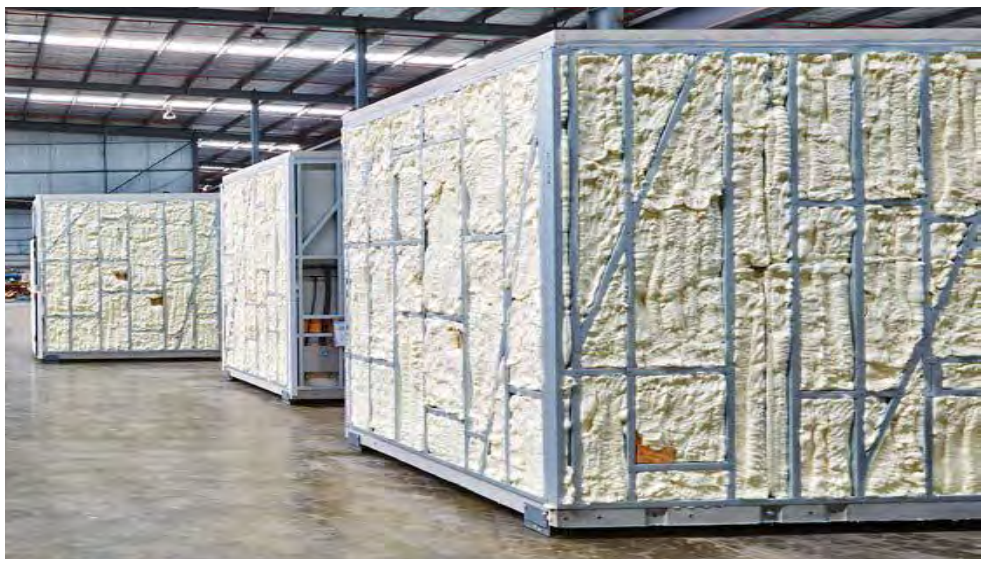

Figure 12: Hickory Building System III.

The HBS are now being used in another 60-level project in Melbourne, and it has been said that the HBS is more beneficial for projects over 30 levels, due to the economies of scale in manufacturing.

\section{CHALLENGES AND A PATHWAY TO SOLUTIONS}

In achieving architecture aesthetics, modern buildings are designed with complexity, and one building is different from another, which brings in one of the challenges for prefabrication: there is not a uniform solution existing for the prefabrication of all buildings. Meanwhile, most of the building codes donet $t$ specify prefabrication construction approaches. Thus building prefabrication needs to be elaborated 
with regard to building design, manufacture, transportation, and module lifting. For example, the decomposition of manufactured building components, module interfaces, and module connections with other modules and with the building are crucial for building prefabrication. More often, people have misconceptions that prefab construction is only of volumetric boxes; while prefabrication is actually a continuum of elements ranging from building components, panels, to volumetric modules, and the degree of prefabrication depends on various factors, including manufacturing technology, transportation regulation and capacity, crane lifting capacity, and so on. In order to achieve optimal outcomes, AEC (architect-engineer-construction) community needs to work closely to develop prefab building products that can reflect their design philosophy and are convenient to be manufactured, transported, and assembled. As displayed in Figure 13, it is intended that a solution to each category might begin with deciding which prefabrication concept is best suited to the solution of the construction stage. The next step is to consider its manufacturing process. Several manufacturing processes might be used within a single construction category. The assembly and delivery are perhaps one of the most important considerations in the entire construction procurement process if prefabrication is to become successful. The intention of the diagram is to simplify the understanding of what prefabrication can mean and provide to part or the entire construction process. It is also important to comprehend the diversity of prefabrication methods that can be implemented throughout the entire construction process. In Australia, it has been an onerous realisation in the take-up of other methods to prefabrication other than mere „volumetric" output. In fact, without perhaps realising it, there are a multitude of pre-fabrication processes already integrated into the delivery of a construction project. Truss frames, wall framing, screw-piles with pre-tensioned concrete panels, bathroom pods, are all examples of prefabricated manufacturing in the residential sector. The proposed integrated prefabrication framework is depicted in Figure 13, in which prefabrication building design leads building manufacturing and results in effects on prefabrication logistics: (1) design professionals need to be aware of the availability of prefabrication design systems, including element components, kit of parts, fill-in, and complete unit, which can be supported by prefabrication building design databases; (2) utilisation of building information modeling (BIM) and design for manufacturing and assembly (DfMA) should also be considered by design professionals to facilitate the design and drafting process of building prefabrication; (3) during the manufacturing process, manufacturing automation is imperative to building manufacturing, and semiautomation and full-automation can be adopted for different building components and by different manufactures; (4) lean manufacturing is also essential to be applied to improve productivity, reduce cost, and minimise waste; and (5) workforce with contributing skill sets is required by the prefabrication industry, as summarized by Daly (2009) .

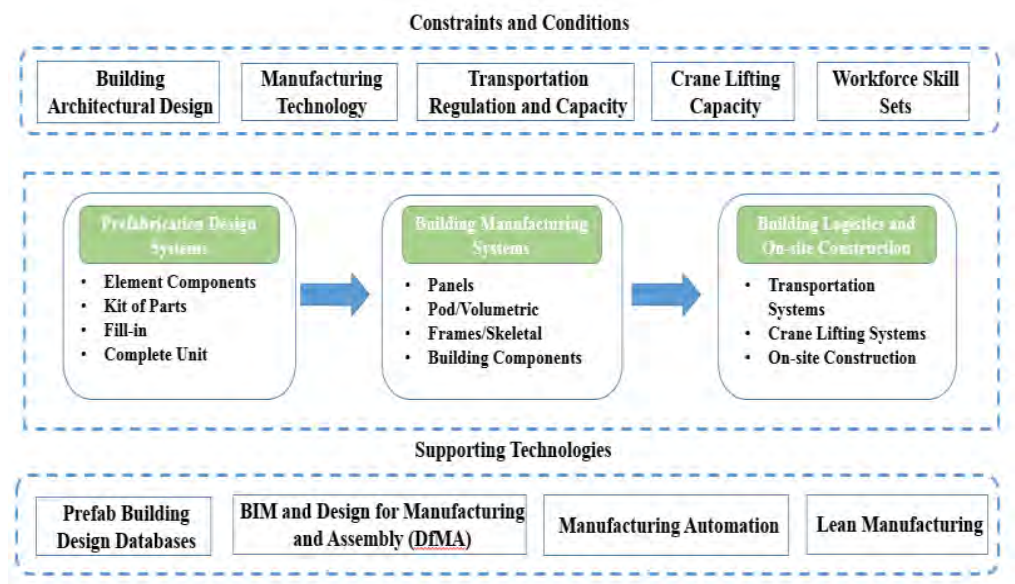


Figure 13: Pathway to Prefabrication and Design Systems.

Although the application of BIM, DfMA, manufacturing automation, and lean manufacturing has been perceived in the industry, the enhancement of these applications is suggested to be pursued to boost the prefabrication in Australia.

\section{REFERENCES}

[1] PrefabAUS, "Everything old is new again", Built Offsite, 1: 9, 2017, http://builtoffsite.com.au/issue-01/historic-perspective-everything-old-new/ (accessed on Sep. 07, 2017).

[2] PrefabAUS, "Prefab in history", 2017, http://www.prefabaus.org.au/prefab-in-history/ (accessed on Sep. 07, 2017).

[3] PrefabAUS, "Prefab and the Australian Building Sector", Built Offsite, 1: 13, 2017, http://builtoffsite.com.au/issue-01/prefab-australian-building-sector/ (accessed on Sep. 07, 2017).

[4] Steinhardt, D.A., Manley, K., and Miller, W., "Profiling the nature and context of the Australian prefabricated housing industry", 2013, https://eprints.qut.edu.au/81176/1/nature-and-contextaustralian-prefabricated-housing.pdf (accessed on Sep. 08, 2017).

[5] Steinhardt, D.A., Manley, K., and Miller, W., "Predicting Australian builderse intentions to use prefabrication", 2014, https://eprints.qut.edu.au/81179/ (accessed on Sep. 08, 2017).

[6] Hickory Building Innovation, "Hickory building systems: overview of prefabricated structural system", 2017, https://www.hickory.com.au/what-we-do/our-systems/hickory-building-systems/ (accessed on Sep. 08, 2017).

[7] Daly, G., "Prefabricated housing in Australia: skill deficiencies and workplace practice", ISS Institute Inc., 2009.

[8] Luther, M., "Towards prefabricated sustainable housing - an introduction", BEDP environment design guide, TEC 28:1-11, 2009. 